\title{
MORFOGÊNESE IN VITRO DE Neoregelia mucugensis Leme
}

\author{
$\underline{\text { Fernanda de Jesus Oliveira Bastos }}^{1}$; Andressa Priscila Piancó Santos Lima²; Alone \\ Lima-Brito ${ }^{3}$ José Raniere Ferreira de Santana ${ }^{4}$ \\ 1. Bolsista PROBIC/UEFS, Graduanda em Agronomia, Universidade Estadual de Feira de Santana, e-mail: \\ nandahhbastos@hotmail.com \\ 2. Doutoranda em Recursos Genéticos Vegetais, Universidade Estadual de Feira de Santana, e-mail: \\ andressapianco@gmail.com \\ 3. Professora, Departamento de Biologia, Universidade Estadual de Feira de Santana, e-mail: lima_brito@yahoo.com.br \\ 4. Orientador, Departamento de Biologia, Universidade Estadual de Feira de Santana, e-mail: jose.raniere@gmail.com
}

PALAVRAS-CHAVE: calogênese; broto; bromélia.

\section{INTRODUÇÃO}

Neoregelia mucugensis Leme é uma espécie típica dos campos rupestres e ocorre no Parque Nacional da Chapada Diamantina, contudo não é considerada protegida devido às extensas queimadas que anualmente atingem este Parque (BELLINTANI, 2006), o que requer estratégias para a sua propagação e conservação.

Neste contexto, a cultura de tecidos vegetais pode ser uma alternativa viável para a propagação desta espécie através da micropropagação.

Esta técnica pode ser desenvolvida através da organogênese a qual ocorre por duas vias distintas: a direta e a indireta. $\mathrm{Na}$ organogênese indireta há a necessidade de desdiferenciação do explante, originando calo antes do estabelecimento das células competentes (BERTOZZO; MACHADO, 2010), portanto, por serem massa celulares indiferenciadas, os calos têm facilidade na regeneração in vitro (KERBAUY, 1997), e permitem a obtenção de elevada taxa de multiplicação.

Neste processo é importante o balanço entre auxina e citocinina. As auxinas atuam na formação de calos, indução do desenvolvimento de nós e de raízes adventícias (CARVALHO; VIDAL, 2003). Já as citocininas induzem, na presença de auxinas, a divisão celular em calos (TAIZ; ZEIGER, 2013).

Há relatos na literatura de trabalhos com o cultivo in vitro de $N$. mucugensis como estabelecimento in vitro (BELLINTANI et al., 2007) e multiplicação via organogênese direta (BELLINTANI et al., 2008). No entanto, os autores consideram estas taxas baixas e sugerem que novas pesquisas sejam realizadas a fim de aumentar a taxa proliferativa. Isto pode ser feito por estudos de organogênese indireta, visto que em geral esta via potencializa a regeneração de brotos. Portanto, o objetivo deste trabalho foi testar diferentes reguladores na morfogênese de Neoregelia mucugensis.

\section{MATERIAL E MÉTODOS}

\section{Material vegetal e meio de cultura}

Plantas germinadas in vitro com 5 meses de idade foram utilizadas como fonte de explantes para realização do experimento. Os explantes foram inoculados em tubos de ensaio $(25 \times 150 \mathrm{~mm})$ contendo $15 \mathrm{~mL}$ de meio de cultura. O meio utilizado foi o MS $1 / 2$ contendo $30 \mathrm{gL}-1$ de sacarose e $7 \mathrm{gL}-1$ de ágar (meio básico). $\mathrm{O} \mathrm{pH}$ do meio foi ajustado para 5,8 antes da autoclavagem, sendo realizada à $121^{\circ} \mathrm{C}$ por 15 minutos.

\section{Efeito do 6-benzilaminopurina - BAP e ácido naftaleno acético - ANA em explantes foliares e caulinares de Neoregelia mucugensis.}

Explantes caulinares com $0,5 \mathrm{~cm}$ e foliares com $1 \mathrm{~cm}$ de comprimento, foram inoculados em meio de cultura básico acrescido de diferentes concentrações de BAP $(0,00$; $4,44 ; 6,66 ; 8,88 ; 11,10 \mu \mathrm{M})$ e ANA $(0,00 ; 2,60 ; 5,20 \mu \mathrm{M})$. O delineamento experimental foi o inteiramente casualizado com arranjo fatorial de $2 \times 5 \times 3$ (dois tipos de explante, cinco 
concentrações de BAP e três concentrações de ANA) totalizando 30 tratamentos cada um composto por cinco repetições com cinco amostras cada e um explante por amostra. Após 60 dias da montagem, foram avaliadas as variáveis porcentagem de explantes com calo (\%EC), área do explante coberta por calo (AEC), coloração e textura dos calos, porcentagem de explantes com broto (\%EB) e número de brotos por explante (NBE).

\section{Efeito do picloram na indução de calos em explantes foliares de Neoregelia mucugensis}

Explantes foliares com $1 \mathrm{~cm}$ de comprimento, foram inoculados em meio de cultura básico acrescido de diferentes concentrações de picloram $(0,00 ; 5 ; 10 ; 15 ; 20 \mu \mathrm{M})$. O delineamento experimental foi o inteiramente casualizado, com cinco tratamentos, cada um com seis repetições com quatro amostras cada e um explante por amostra. Após 60 dias da montagem, foram avaliadas as variáveis porcentagem de explantes com calo (\%EC), coloração e textura dos calos.

\section{Condições experimentais}

$\mathrm{O}$ experimento foi mantido em sala de crescimento com temperatura de $26 \pm 3^{\circ} \mathrm{C}$, e mantido no escuro.

\section{Análise dos dados}

Os dados foram submetidos à análise de variância (ANOVA) utilizando o programa estatístico SISVAR 5.1 (FERREIRA, 2003) e as médias analisadas por regressão ou comparadas pelo Teste de Tukey a $5 \%$ de probabilidade.

\section{RESULTADOS}

A análise de variância apontou efeito significativo $(p \leq 0,05)$ apenas para o tipo de explante, nas duas variáveis avaliadas: porcentagem de explantes responsivos (\%ER) e número de brotos por explante (NBE).

Para ambas as variáveis (\%ER e NBE) o explante caulinar apresentou diferença estatística significativamente superior ao explante foliar (Tabela 1), isto pode ter ocorrido devido a maior presença de tecido meristemático e gemas laterais no explante caulinar, visto que a formação de brotos ocorreu por organogênese direta. Não foi observada a presença de calos em ambos os tipos de explantes. Estes resultados indicam que as concentrações dos reguladores utilizadas não foram eficientes para induzir a regeneração de brotos por organogênese indireta.

As concentrações dos reguladores utilizados não apresentaram diferença estatística significativa, no entanto a regeneração de brotos ocorreu em todos os tratamentos testados para o explante caulinar, inclusive na ausência de reguladores vegetais, o que é vantajoso pois reduz os custos de produção.

Resultado divergente foi encontrado por Belllintani et al. (2008) em estudo realizado também com Neoregelia mucugensis no qual as melhores taxas de regeneração de brotos a partir de explantes caulinares por organogênese direta ocorreu na combinação de 2,22 ou 4,44 $\mu \mathrm{M}$ de BAP com 1,30 $\mu \mathrm{M}$ de ANA, e houve formação de calos em 10,2\% dos explantes após 4 meses de cultivo in vitro.

A formação de brotos pela via direta da organogênese também foi observada por Carneiro et al. (1999) que avaliaram o efeito da combinação de diferentes concentrações de BAP e ANA em explantes foliares de Neoregelia cruenta e obtiveram os melhores resultados para porcentagem de explantes com brotos e número de brotos por explantes na associação desses reguladores. 
Tabela 1. Porcentagem de explante responsivo (\%ER) e número de brotos por explante (NBE) em função do tipo de explante.

\begin{tabular}{lll}
\hline Explante & $\% \mathrm{ER}$ & $\mathrm{NBE}$ \\
\hline Folha & $0 \mathrm{~B}$ & $0 \mathrm{~B}$ \\
Caule & $68,77 \mathrm{~A}$ & $1,92 \mathrm{~A}$ \\
\hline
\end{tabular}

Médias seguidas pelas mesmas letras, maiúsculas nas colunas não diferem entre si pelo teste de Tukey a 5\% de probabilidade de erro.

A ocorrência da regeneração de brotos por organogênese indireta foi obtida por Lima (2016) em estudo com Orthophytum mucugense a partir de explantes foliares na interação entre ANA e BAP. O mesmo foi relatado em estudos realizados por Pineda, Vargas e García (2014) que utilizando segmentos foliares basais de Ananas comosus (L.) Merr conseguiram na combinação de $26,85 \mu \mathrm{M}$ de ANA com $1,11 \mu \mathrm{M}$ de BAP brotos formados a partir de calos, diferindo do resultado demonstrado no presente trabalho com $N$. mucugensis no qual a regeneração pela via indireta não foi obtida.

Visando aumentar a taxa proliferativa da espécie outras concentrações desses reguladores vegetais podem ser testadas.

Para o uso do picloram, a análise de variância apontou efeito significativo $(p \leq 0,05)$ para as concentrações de picloram na variável porcentagem de explante responsivos (\%ER). Não houve formação de calos na ausência de regulador vegetal, esta foi observada nos explantes sob efeito do picloram, que apresentaram textura friável e coloração bege.

Em relação ao efeito do picloram sobre a \%ER a análise de regressão apresentou o modelo polinomial quadrático como mais representativo para esta variável, demonstrando que o acréscimo desse regulador ao meio de cultura promoveu um aumento na taxa de explantes com formação de calos atingindo o ponto máximo na concentração de $12,96 \mu \mathrm{M}$ com valor máximo estimado de 75,96\% (Figura 1). A partir deste ponto ocorre uma diminuição na taxa de explantes responsivos. Nota-se que na ausência de regulador não houve formação de calos, isto demonstra a importância dessa auxina nesse processo, corroborando Pacheco et al. (2012) que afirmam que o picloram é uma auxina que promove alta indução de calos.

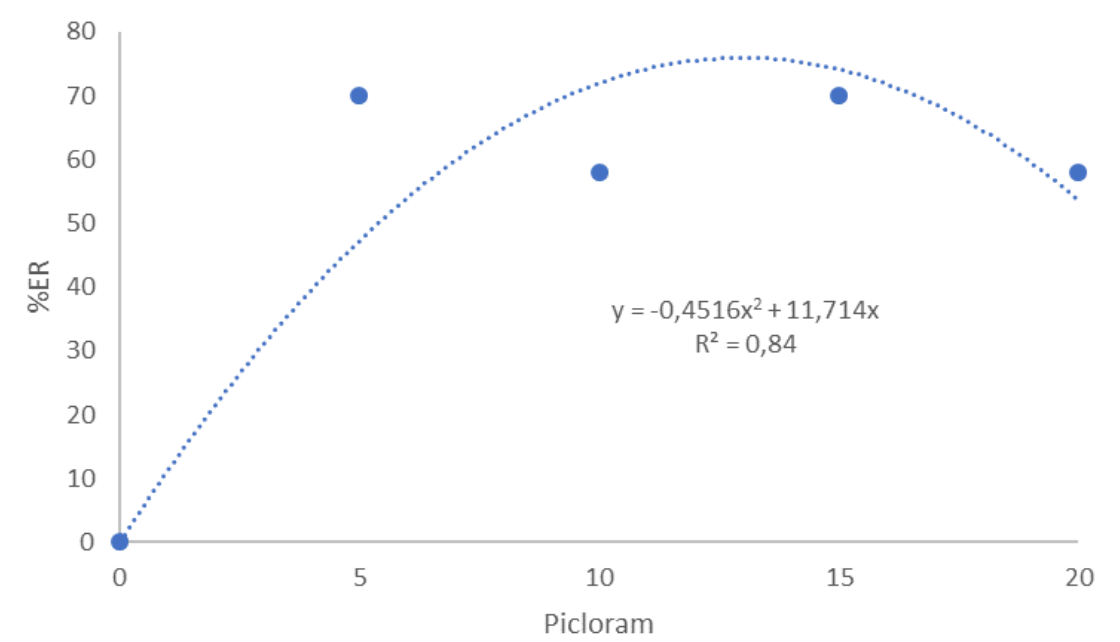

Figura 1. Porcentagem de explantes responsivos (\%ER) em função de diferentes concentrações de Picloram em explantes foliares de Neoregelia mucugensis após 60 dias de cultivo in vitro. *Significativo a $5 \%$ de probabilidade.

Estes resultados podem indicar que possivelmente os explantes foliares de $N$. mucugensis já apresentam alta concentração de auxina endógena, sendo a aplicação exógena 
de baixas concentrações suficientes para induzir a formação de calo, tendo efeito inibitório para as concentrações mais elevadas.

Os vegetais possuem, naturalmente, hormônios vegetais, que em baixas concentrações podem induzir, modificar ou inibir seus processos fisiológicos, e com ações semelhantes a estes há reguladores vegetais sintéticos que podem ocasionar tanto a promoção quanto a inibição de processos metabólicos relacionados ao crescimento e desenvolvimento da planta (ALBUQUERQUE; MOUCO; ALBUQUERQUE NETO, 2008).

\section{CONSIDERAÇÕES FINAIS}

Os reguladores vegetais BAP e ANA, nas concentrações utilizadas, não são eficientes para a regeneração de brotos via organogênese indireta em explantes foliares e caulinares. A organogênese direta de $N$. mucugensis é obtida a partir do explante caule em meio livre de regulador vegetal. $\mathrm{O}$ uso da auxina Picloram promove a calogênese no explante folha de $N$. mucugensis.

\section{REFERENCIAS}

ALBUQUERQUE, T. C. S. de; MOUCO, M. A. do C.; ALBUQUERQUE NETO, A. A. de. Reguladores de crescimento vegetal na concentração de macronutrientes em videira Itália. Bragantia, p. 553-561, 2008.

BELLINTANI, M. C. et al. Estabelecimento in vitro de Orthophytum mucugense e Neoregelia mucugensis, bromélias endêmicas da Chapada Diamantina, Bahia - Brasil. Revista Brasileira de Biociências, Porto Alegre, v. 5, supl. 2, p. 1101-1103, jul. 2007.

BELLINTANI, M.C. et al. Resposta regenerativa in vitro de explantes caulinares de bromélias endêmicas da Chapada Diamantina- Bahia. Magistra, v.20, n.4, p.328-337, 2008.

BERTOZZO, F., MACHADO, I. S. Meios de cultura no desenvolvimento de ápices caulinares de mamoneira (Ricinus communis L.) in vitro. Ciência e Agrotecnologia, Lavras, v. 34, n. 6, p. 1477-1482, 2010.

CARNEIRO L. A. et al. In vitro regeneration from leaf explants of Neoregelia cruenta (R. Graham) L.B. Smith, an endemic bromeliad from Eastern Brazil. Plant Cell Tissue Organ Cult. 55:79-83, 1999.

CARVALHO, J. M. F. C.; VIDAL, M. S. Noções de Cultivo de Tecidos Vegetais. Campina Grande, 2003.

FERREIRA, D.F. SISVAR Sistema de análises estatísticas. Lavras: UFLA, v.3, n.4. 2003.

KERBAUY, G. B. Clonagem de Plantas in vitro. Biotecnologia Ciência e Desenvolvimento. 1997.

LIMA, A.P.P.S. Micropropagação e conservação in vitro de Orthophytum mucugense Wand. e Conceição. 2016. 92f. Dissertação (Mestrado) - Universidade Estadual de Feira de Santana, Feira de Santana, 2016.

PACHECO G, G. R, L. D, V. M \& M. E Plant regeneration, callus induction and establishment of cell suspension cultures of Passiflora alata Curtis. Scientia Horticulturae, 144:42-47, 2012.

PINEDA, A.; VARGAS, T. E.; GARCÍA, E. G. de. Regeneración de Ananas comosus (L.) merr, ecotipo tabë känä, mediante organogénesis indirecta. Bioagro, v. 26, n. 3, p. 135-142, 2014.

TAIZ, L.; ZEIGER, E. Fisiologia Vegetal. 5. ed. São Paulo: Artmed, 2013. 